\title{
The Cooperation Between China and the United Nations Framework Convention on Climate Change
}

\author{
Yuxin $\mathrm{Ma}^{1, \dagger}$ Fanbo $\mathrm{Nie}^{2, *, \dagger}$ Yiran Wang ${ }^{3, \dagger}$ Yongdong $\mathrm{Zhou}^{4, \dagger}$ \\ ${ }^{1}$ China Foreign Affairs University, Beijing, China \\ ${ }^{2}$ The Political Economy of Emerging Markets, School of Global Affairs, Department of International Development, \\ Faculty of Social Science \& Public Policy, King's College London, UK \\ ${ }^{3}$ Shanxi Provincial People's Hospital, Shanxi, China \\ ${ }^{4}$ Hangzhou No.14 Middle School, Zhejiang, China \\ *Corresponding author. Email: ${ }^{2}$ fanbo.nie@kcl.ac.uk \\ ${ }^{\dagger}$ Theseauthorscontributedequally.
}

\begin{abstract}
The United Nations Framework Convention on Climate Change (UNFCCC) is one of the most important treaties to reduce carbon emission in the scale of international cooperation. The relationshipbetween China and UNFCCC is significant. China's role in the frameworks of global warming protection attracts more and more attention since it emits the most $\mathrm{CO} 2$ gas in recent years. To better illustrate this relationship in multilateral conflicts, this article scrutinizes the history with a vision for future cooperation.
\end{abstract}

Keywords: United Nations Framework Convention on Climate Change (UNFCCC), international cooperation, greenhouse gas emission.

\section{INTRODUCTION}

UNFCCC stands for United Nations Framework Convention on Climate Change. It is a Multilateral environmental agreement signed on 14 June 1992. The UNFCCC aims to stabilize greenhouse gas concentrations in the atmosphere at a level that would prevent dangerous human interference with the earth's climate system. Such a level should be achieved quickly enough to allow ecosystems to adapt naturally to climate change, ensure that food production is not threatened, and enable economic development to proceed sustainably [1].

The treaty established different responsibilities for three categories of signatory states: developed countries, developed countries with special financial responsibilities, and developing countries. Annex I countries are called upon to adopt national policies and take corresponding measures to mitigate climate change by limiting their anthropogenic emissions of greenhouse gases and reporting on steps adopted to return individually or jointly to their 1990 emission levels [1]. The developed countries with special financial responsibilities are also called Annex II countries. They are called upon to provide new and additional financial resources to meet the costs incurred by developing countries in complying with their obligation. The developing countries are then required to submit their inventories to the UNFCCC Secretariat.

This Convention is the parent treaty of the 1997 Kyoto Protocol and the 2015 Paris Agreement. The main goal of the Kyoto Protocol was to control emissions of the main human-emitted greenhouse gases in ways that reflect underlying national differences in greenhouse gas (GHG) emissions, wealth, and capacity to make the reductions [2]. The main aim of the Paris Agreement is to keep the global average temperature rise this century as close as possible to 1.5 degrees Celsius above preindustrial levels.

\section{BACKGROUND OF CHINA JOINING THE UNFCCC AND ITS BENEFITS}

Recognizing that climate change is a global challenge, China has actively responded to climate change and has played an important role in UNFCCC.It ratified the United Nations Framework Convention on Climate Change by the National People's Congress on November 7, 1992. It deposited the instrument of ratification with the United Nations Secretary-General on January 5, 1993. On May 29, 1998, Ambassador Qin 
Huasun, Permanent Representative of China to the United Nations, signed the Kyoto Protocol at the Secretariat of the United Nations, on behalf of the Chinese Government. China is the 37th signatory. On September 3, 2016, the Standing Committee of the National People's Congress of China approved China's accession to the Paris Climate Change Agreement, becoming the 23 contracting parties that have completed the ratification of the Agreement.

In the early 1990s, China's air was severely polluted by the over-industrialized gas emissions, China's water was critically muddled by uncensored trash from human activities, and China's biodiversity was also unbelievably ruined. At that time, China is encountered shocking environmental problems: the drying up of the Yellow River and the Yangtze River, the flooding of the Yangtze River and the Asian Dust, and the drastic reduction in the forest [3]. Some people blame the rivers' drying up to the growth of industry and agriculture and the cities' increasing need for water. The Research Institute for Humanity and Nature (RIHN) says the case was not that simple, and deforestation was the main cause for this. The severe flooding of the Yangtze River was also caused by the greedily clearing of forests for farmlands. Deforestation also caused many other problems, taking the quality of the air for instance, until the early 1990s, less than $1 \%$ of 500 cities in China met the national air quality standards. As the following elements,some air elements were over exceedingly beyond the standard amount of $\mathrm{mg}$ per $\mathrm{m}^{3}$, like $\mathrm{SO} 2, \mathrm{NO} 2, \mathrm{NOX}, \mathrm{NO} 3$, and $\mathrm{CO}$ [3]. This situation is far lower than the standard of the UNFCCC.China's increasing energy consumption with a strong reliance on coal also led to polluted air. All these deteriorated environmental problems caused vital public health setbacks and economic damage.

China has woken up from the nightmare of a deadly twisted environment and taken various kinds of measures to upgrade under the framework of the UNFCCC since the early 1990s. The UNFCCC urges China to pledge to cut CO2 emissions per unit of GDP 40\%-45\% from 2005 levels by 2020 , which happened before the Copenhagen Conference in 2009. This seemed like a big challenge for China since it had been used to extensive economic growth ways for a very long time. In 2014, the UNFCCC urged China and the USA to cooperatein negotiations to address global climate change and to reach a global agreement. Under the guidance of the UNFCCC, China also submitted its Intended Nationally Determined Contribution (INDC) in June 2015. In this INDC, China pledged to peak its carbon dioxide emissions around 2030 and make the greatest efforts to peak earlier. It also pledged that by 2030 , it would lower carbon dioxide emissions per unit of GDP 60\%-65\% from the 2005 level, increase the share of non-fossil fuels in main energy consumption to around $20 \%$ and increase the forest stock volume by around 4.5 billion cubic meters from the 2005 level. At this time, China is much more confident and active in realizing the goals since the previous efforts have laid a good foundation for further achievements. The progressed economy empowered it to invest more financial strength to the realization. On the 24th Conference of the Parties to the UNFCCC in 2018, the "Paris Rule Book"is a detailed set of requirements on topics that include monitoring, reporting, and verification of emissions. Compromising with the EU and other developed countries, China accepted a common set of standards for all Parties, with some flexibility for developing country Parties to implement. On the G20 Summit in 2019, China confirmed to update its Nationally Determined Contributions in a manner representing a progression beyond the current one and reflecting its highest possible ambition," and to publish "long-term mid-century low greenhouse gas emissions development strategies" by 2020.

China has been shifting from a giant $\mathrm{CO} 2$ emission body to a rising green power. It has implemented multitudes of laws, regulations, and standards to upgrade the environment. It has installed various kinds of organs to protect the environment, like the Environment and Resources Protection Committee, the State Environmental Protection Commission of the State Council, and the State Environmental Protection Agency of the State Council. China also has established a national air pollution monitoring system, implemented research and development for urban air pollution control, and invested in environment infrastructure, including pollution control devices- Currently, routine urban air quality monitoring of the pollutants SO2, TSP, and NOx. are conducted by more than 350 cities. China's national air monitoring system (NAMS) was formed by 103 municipal atmospheric monitoring stations with 470 monitoring sites. In the early 1980 s, acid rain monitoring began, which mainly focuses on the urban districts in the south and southeast. The National Acid Deposition Monitoring Net (NADMN) nowadays includes 113 monitoring stations and 300 monitoring sites all over the country - this contrast indicates fast progress achieved. The development of the investment in environmental infrastructure has also leaped, including cleaner production technology, pollution control devices, and natural gas pipelines, etc.

However, there are still some doubts and critics against China's benefits from the UNFCCC. The question remains as to what China's global climate leadership role can be. Within the UN system, the climate issue offers China a field in which it is much easier to build up a positive reputation than in other fields such as human rights and labor rights. However, to better understand China's global leadership approach, it is more helpful to look outside of the UN system. One can observe that China is seeking global influence through heavy infrastructure investments abroad. Two Chinese banks are the world leaders in global energy finance, but their investment portfolio is still based on fossil 
investments, such as coal-fired power plants. China's investment in neighboring Arctic countries shows that China wants to secure access to this region and to its natural resources. Additionally, the "One Belt One Road" initiative represents major investments designed to secure access to export markets in the long run. All of these initiatives might dilute or run counter to the global effect of domestic low-carbon developments-- China's self-evident goal in continue to take advantage of the heavy industry with a compromised strategy aligned with most of the other countries' unsustainable developing tactics makes it hypocrisywhich is strongly trying to be a clean-energy producer and partner while a weak and dirty dealer that cannot resist the temptation from the benefits of heavy industry.

China joined the environmental revolution much later than most of the western countries. Yet, it has been insisting at the frontline of the battle against the climate issues when the US withdrew from the dazzling position of the tycoon, and this has made China the biggest beneficiary in the world arena of almost everything, since losing the power of the discourse of the environmental issues is losing all the world. However, China is doubted to be a bully [4-6] to the international orderbecause it is getting arrogant and aggressive after an uplifted reputation on earth, mainly with its overwhelmingly brilliant shot in addressing environmental problems. The US had experienced a long period of being isolated by others when it took a high profile against the rest part of the world. Still, China seems not to have learned this lesson of the US. The benefits that it gained from the victory in the environment war give it a chance to boost its ability to deal with international issues, while more and more countries are suffering from its willful tricks in manipulating the world with the ambition to maximize its own benefits and authority to rule others.

\section{EXAMINE CHINA'S CONTRIBUTIONS}

China has made important contributions to the conclusion of the Paris Agreement on Climate Change and is an active participant in the implementation of the Agreement. China joined the Paris Agreement on Climate Change in 2016, fulfilled part of its commitments under the Paris Agreement in 2018 three years ahead of schedule, and fully fulfilled its commitments by 2020. China is one of the world's two largest economies and the largest annual carbon producer. Governance of climate change must have China's participation to achieve good results.President $\mathrm{Xi}$ announced that China will increase contributions to climate change and adopt more robust policies and measures to achieve a peak in carbon dioxide emissions by 2030 and carbon neutrality by 2060. Specifically, China will reduce carbon dioxide emissions per unit of GDP by more than 65 percent from 2005 levels, increase the share of non-fossil energy in primary energy consumption to about 25 percent, increase forest stock by 6 billion cubic meters over 2005, and increase the total installed capacity of wind and solar power to more than 1.2 billion kilowatts by 2030 .

In addition, China is speeding up the construction of carbon exchanges. Previously, there were seven pilot carbon markets in China, covering more than 20 industries, including steel and electricity. After more industries are added to the carbon market this year, the National Carbon Exchange will be opened on June 25. Carbon exchanges allow companies to buy and sell their share of carbon emissions. The establishment of the carbon exchange reflects China's determination to strictly enforce the carbon emission measures.

Nowadays, the United States, China, and the European Union are the three economies that significantly impact climate change. China's contribution to the UNFCCC and global climate governance has been particularly prominent in some cases. The Trump administration has taken unprecedented steps backward in climate change policy. Trump's isolationism has caused significant damage to the relation between the United States and Europe and the global climate governance process. If China and the EU did not stand firm, the Paris agreement was likely to fail, and if consensus on controlling climate change is lost, the outcome could be catastrophic.

Fortunately, the Biden administration has actively corrected the Trump administration's policies. The U.S. return to the Paris Agreement under the policy of "return to multilateralism" and "return to climate" has been widely recognized by the international community. Today, China, the United States, and the EU have a great consensus on enhancing the contribution and cooperation of big countries to promote climate change. Both the United States and the EU regard China as an indispensable participant in global climate change governance. In the future, China's contribution to the UNFCCC will be further reflected in the cooperation between major countries. However, there are some potential issues with close cooperation between countries. If the conflict between China and the United States escalates, the United States may also put climate issues in the framework of its competition with China [7]. For example, they may ask China to make more commitments and contributions to climate change governance, criticizing the Belt and Road Energy projects or setting western-led green technology and green finance standards $[5,6]$. China should pay close attention to and properly handle the issues related to climate change policy and balance the national interest with the responsibility for climate change as much as possible so that the current situation can be maintained or even improved.

Moreover, the impact of China-style climate change policies in the world is likely to be limited. It is possible 
for China to peak its emissions by 2030, provided that all existing policies are fully and effectively implemented [8]. Chinese government's ability to intervene in the market is an important reason China is likely to achieve its carbon peak goal. The authoritarian government, for example, can force some of its most polluting industries to shut down or relocate to less environmentally sensitive areas. However, in other capitalist countries in the world, the market is determined by capital, the power of the government is often limited, and it is very difficult to implement mandatory measures against enterprises. At the same time, some of the most effective reforms are also difficult to implement with the intervention of various stakeholders. Thus, the rest of the world cannot make policies by copying the "China model" completely. Any policy formulation needs to consider the actual situation of the specific country better.

Finally, the issue of "ecologically unequal exchange" is also worth discussing. The idea refers to the transfer of polluting waste or enterprises by rich countries to other disadvantaged or developing countries to improve the rich countries' ecological environment [9]. China's domestic environmental improvement should not come at the expense of its neighbors' ecological environment. China does not seem willing to compromise in bilateral or multilateral relations on issues that could directly impact its environment. For example, China and Laos, Thailand, Cambodia, and Vietnam have been unable to manage the Mekong River. Some criticized that China is reluctant to engage in water-sharing cooperation with the lower Mekong countries [10]. On the one hand, China promotes multilateralism internationally, but on the other hand, it does not care about the cooperative governance of Mekong river countries. In 2020, however, the Mekong dispute gained momentum when China said it was willing to share data on the river's water resources. That could be an important sign that China is willing to cooperate on the issue further.

\section{EXPECTATIONS FOR FURTHER COOPERATION BETWEEN CHINA AND THE UNFCCC}

COP26, delayed due to covid-19, will be held in 2021. In this conference, the role of China will be important since its actions will directly affect the environment and the model to other countries. According to UN Climate Change Conference UK 2021, the basic and the most important thing in COP26 is to "secure global net zero by mid-century and keep 1.5 degrees within reach" [11]. To achieve this, future cooperation between China and the UNFCCC can be enforced through the political, technology, and media perspectives.

Firstly, China needs to cooperate with the UN to achieve sustainable development. One of the most important reasons to explain high carbon emissions in
China is the lack of thoughts on protecting the environmentand sustainable development. Some citizens think that economic development is the most important thing for China. They believe that sacrificing the environment for the economy could be appropriate. In the previous COP, once a "Chinese delegate insisted on tinkering with the $1.5^{\circ} \mathrm{C}$ temperature target until it was largely meaningless" [12]. Even the Chinese staff who took part in the conference didn't understand the importance of reducing carbon emissions and sustainable development, let alone citizens. Therefore, the Chinese government needs to follow publicity strategies about environmental protection from UNFCCC. For instance, a research that: "in the few months where carbon taxes do have a statistical impact, GDP changes are mostly positive" since it can change some Chinese' stereotype that environment protection will harm the economy [13]. As for the specific cooperation, China can send famous celebrities to the UN to advertise the importance of reducing carbon dioxide emissions. By doing so, the Chinese will imitate these good behaviors from celebrities, like movie stars in China. Also, China needs to use the internet to do some advertisements about sustainable development frequently. By coopering, the thoughts of environmental protection and sustainable development can be widely spread in China.

In addition to that, China can share advanced technology used to produce renewable resources with UNFCCC. The reason why we have a higher amount of $\mathrm{CO} 2$ in the air is that people overuse some resources, which will create quantities of greenhouse gases and make a detrimental impact on the environment. From the report "the Amazon rainforest is already releasing more greenhouse gases than it absorbs", we can directly understand the trend of the environmental problem and why we need to reduce carbon emissions [11]. One of the most effective ways to deal with this problem is by using advanced technologies. In China, the development of technology makes the use of renewable resources possible, so China can cooperate with UNFCCC to share these techniques with it, which can help alleviate this problem all over the world. According to Bloomberg New Energy Finance, "China surpassed the United States in its investment in renewables by 2012". This evidence shows that cooperation is realistic and necessary. China can also benefit from this cooperation in the future since they can ask something for exchange due to the share of techniques. For instance, China is good at exploiting tidalenergy. By sharing the techniques of using tidal energy with UNFCCC, more countries can access renewable resources instead of using traditional resources, which is harmful to the environment. China can also benefit from the cooperation since "tidal energy has reached a very high level of commercialization" [14].

Last but not least, China needs to follow the advice from UNFCCC to increase the price of carbon dioxide. A carbon price sends a financial signal to investors that low- 
carbon investments are valuable today and will be even more valuable in the future [15]. This evidence indicates that price increases can show a trend to investors in China that carbon gradually will not be used in the long run. By doing so, investors will gradually stop investing carbon since they will gain loss in the future. In the long run, it will surely help to reduce carbon dioxide emissions in China. Nevertheless, in the short-run, carbon dioxide emissions will even increase since "a decline in coal and crude oil prices increases demand for coal and oil" [16]. This economic relationship indicates that the government also needs to find ways to deal with this problem in the short-run. In this case, following the other advice from the UN, which is setting a carbon tax, becomes important. If the government sets a carbon tax, the profit that Chinese investors can gain will decrease, which will reduce their incentives of carbon investment $[17,18]$. By following this advice from the UN, carbon dioxide emission will surely decrease in China.

\section{CONCLUSION}

China has long been making harmony with its development and the ecological environment. Without the strategy of globalization and cooperation under the framework of the UNFCCC, it cannot address the everincreasingly severe environmental problems. China has made a great testimony of cooperation with the UNFCCC that could benefit all sides of our planet. According to the principles of the Paris Agreement, China set different temporary goals that will eventually make an ultimate goal realized. This deepened, and globalized strategy has helped its vision to come true. Suppose the environment of China is improved and the climate change is well addressed. In that case, people will live comfortably in a very human and bio-diversity friendly place, which will improve the economic productivity that can eliminate poverty and contribute to further investments into more upgrading of the environment.

\section{REFERENCES}

[1] H. K. Jacobson, EB Weiss. (2000). Strengthening compliance with international environmental accords: preliminary observations from Collaborative Project, Global Governance, HeinOnline

[2] Grubb, M. (2004). Technology innovation and climate change policy: an overview of issues and options. Keio economic studies, 41(2), 103-132.

[3] China's Environmental Problems and Prospects for Japanese Cooperation- JumpeiKutoba, 2016. Retrieved July 24, 2021, from Journal of Contemporary East Asia Studies.

[4] Beijing's Global Arrogance Is Souring Public Opinion on China. (n.d.). Retrieved August 14,
2021 ,

from

https://foreignpolicy.com/2021/08/13/china-

arrogance-reputation-racism-united-states-

mistakes/

[5] The Man Behind China's Aggressive New VoiceThe New York Times. (n.d.). Retrieved August 14, 2021 , from https://www.nytimes.com/2021/07/07/magazine/ch ina-diplomacy-twitter-zhao-lijian.html

[6] Understanding how China is championing climate change mitigation-Anita Angles, 2018. Retrieved July 31, 2021， from https://www.nature.com/articles/s41599-018-01504

[7] Dong, Y., \& Sun, C. (2021). Climate Change Policies in the EU and US: Divergences and Cooperation Prospects. International Studies, 63(4), 103-119. http://www.ciis.org.cn/gjwtyj/dqqk/202107/P02021 0719472054035793.pdf

[8] Gallagher, K.S., Zhang, F., Orvis, R. et al. Assessing the Policy gaps for achieving China's climate targets in the Paris Agreement. Nat Commun 10, 1256 (2019). https://doi.org/10.1038/s41467-019-091590

[9] Moran D.D, Lenzen M, Kanemoto K, Geschke A (2013) Does Ecologically Unequal Exchange Occur? Ecological Economics 89177-89186.

[10] Chellaney B (2012) Asia's worsening water crisis. Survival 54(2), 143- 156.

[11] Page, M. L. (2021). "Make or break" is hardly hyperbole for the climate negotiations due to reach their climax in November in Glasgow, UK. At the COP26 meeting, nations will have a last chance to really rev up the stuttering motor of climate action and come good on commitments made in Paris in 2015 to limit global warming to a "safe" level of $1.5^{\circ} \mathrm{C}$. New Scientist, 250(3331), 34-45. https://ukcop26.org/cop26-goals/

[12] Lynas, M. (2010). How China made it an unfair COP. New Statesman, 139(4982), 34.

[13] Bernard, J.-T., \&Kichian, M. (2021). The Impact of a Revenue-Neutral Carbon Tax on GDP

Dynamics: The Case of British Columbia. Energy Journal, 42(3), 205-223. https://doi.org/

10.5547/01956574.42.3.jber.

[14] China's Greenhouse Gas Emissions Exceeded the Developed World for the First Time in 2019. (2021, May 6). Rhodium Group. https://rhg.com/research/chinas-emissions-surpassdeveloped-countries/ 
[15] Calls Increase to Use Carbon Pricing as an Effective Climate Action Tool | UNFCCC. (2020, September 22). https://unfccc.int/news/calls-increase-to-usecarbon-pricing-as-an-effective-climate-action-tool

[16] China Is Leading the Clean Energy Revolution, Clean Energy Finance Forum. (2019, January 28). https://www.cleanenergyfinanceforum.com/2019/0 1/28/china-is-leading-the-clean-energy-revolution

[17] Sweden's Carbon Tax: Looking Back on 30 Years of Carbon Taxes. (2020, September 23). https://taxfoundation.org/sweden-carbon-taxrevenue-greenhouse-gas-emissions/

[18] Guo Z, Zhang X, Wang D, Zhao X. The Impacts of an Energy Price Decline Associated with a Carbon Tax on the Energy-Economy-Environment System in China. Emerging Markets Finance \& Trade. 2019;55(12):2689-2702. 